\title{
o corporativismo económico como doutrina e dispositivo: o sistema português em perspectiva comparada (1933-1974) ${ }^{\star}$ the economic corporatism as doctrine and gimmick: the portuguese system in a comparative perspective (1933-1974)
}

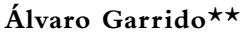 \\ Faculdade de Economia, Universidade de Coimbra, Coimbra, Portugal
}

\section{RESUMO}

Este artigo incide no conceito e nas práticas institucionais de corporativismo económico no ambiente histórico dos fascismos europeus e no contexto específico do Estado Novo português. Partindo da constatação de que o conceito de corporativismo económico se encontra sub-representado na historiografia, analisa-se em que medida as organizações corporativas da economia mostraram características comuns a outros movimentos de regeneração institucional do capitalismo no período entre as duas guerras mundiais. Fazendo uma síntese comparativa dos regimes do fascismo italiano, do nazismo alemão, da França de Vichy e da Espanha de Franco, identificam-se as características institucionais e as singularidades desses modelos de corporativismo económico. Dada a sua relevância internacional na vaga internacional de sistemas de corporativismo de Estado, e considerando a longevidade das suas instituições, tomamos como estudo de caso a organização corporativa da economia vinculada ao Estado Novo português. A lógica política e instrumental do sistema de governo da economia que persistiu em Portugal entre 1933 e 1974

\begin{abstract}
This article focuses on the concept and institutional practices of economic corporatism on the historic ambience of the European fascisms and in the specific context of the Portuguese New Sate. Starting from the evidence that the concept of economic corporatism is under-represented in historiography, we debate to what extent the corporatist organizations have shown common features comparing to other movements engaged in the institutional regeneration of the capitalist system during the interwar period. Making a comparative synthesis of the regimes of Italian fascism, German $\mathrm{Na}$ zism, France of Vichy and Spain of Franco, we identify the institutional features and singularities of those models of economic corporatism. Given its international relevance in the international wave of state corporatism, and considering the longevity of its institutions, we take as case-study the corporatist organization for economy connected with the Portuguese New State. The politic and instrumental logic of the economic guidance system that lasted in Portugal between 1933 and 1974, allows to
\end{abstract}

\footnotetext{
* Submissão: 16/02/2019; aprovação: 13/11/2019.

$\star \star$ Professor catedrático da Faculdade de Economia da Universidade de Coimbra. E-mail: agarrido@fe.uc.pt. ORCID: <https://orcid.org/0000-0001-5424-8923>.
} 
permite revisitar as potencialidades e limitações do conceito de corporativismo económico enquanto categoria de análise histórica.

Palavras-chave: Corporativismo. Economia. Instituições. Fascismos. Portugal. revisit the potentials and limitations and constraints of the concept of economic corporatism as a tool of historic analysis.

Keywords: Corporatism. Economy. Institutions. Fascisms. Portugal.

\section{Corporativismo, corporativismos}

Nos seus diversos tempos e modalidades, o corporativismo consiste numa ideia funcional. Estamos perante uma doutrina destinada a assegurar a ordem social num determinado espaço (Estado-Nação ou empresa) e a promover a conciliação entre os interesses individuais associados a uma profissão ou actividade económica e um determinado interesse colectivo cuja garantia é confiada ao poder político ou a instâncias que o representam.

Entre as duas guerras mundiais, a crise do Estado liberal e a erosão institucional do próprio capitalismo - de certa forma, a crise do mercado - estimularam uma intensa e variada reflexão sobre as relações entre a economia, a sociedade e a política.A solução corporativa oferecia respostas político-institucionais para a superação do Estado liberal e para uma transformação compulsiva da economia de mercado e das instituições do capitalismo concorrencial herdadas do século XIX (Berend, 2006, p. 18-31).

No seu voluntarismo doutrinário, em geral os corporativistas prometiam novas formas de governo da economia e pretendiam garantir a disciplina das relações de trabalho ou o fim do sindicalismo livre. No contexto autoritário e totalitário dos fascismos europeus e sul-americanos do primeiro pós-guerra e dos anos trinta, esses propósitos traduziram-se, fundamentalmente, num intervencionismo económico sem precedentes, imposto segundo lógicas de autarcia e proteccionismo comercial, e na liquidação do sindicalismo revolucionário. Nas mais diversas experiências nacionais (Pinto, 2017; Pasetti, 2016, p. 103-189), o corporativismo apresentou-se como solução para uma questão central da política moderna: o problema da conciliação entre a diversidade dos interesses económicos e sociais e a construção da unidade política do Estado, fosse ele autoritário ou totalitário. 
Os corporativistas insistiram em declarar que a Grande Guerra e a crise de 1929 não eram fenómenos contingentes, mas depressões cíclicas que abriram uma grande fractura na economia liberal, como que revelando a deficiência orgânica do sistema capitalista e a sua propensão para gerar instabilidade. À competição e anarquia da produção e repartição de riqueza em que caíra o liberalismo, o corporativismo opunha a solidariedade de todos os elementos da vida económica, obrigando-os a exercer a sua actividade com espírito de paz social. Debaixo desta dogmática composta por diversos afluentes doutrinários e ideologias geralmente contra-revolucionárias, escondiam-se finalidades instrumentais convergentes com a lógica política dos regimes autoritários, em geral, e dos fascismos-regime, em particular.

De acordo com a definição de Philippe Schmitter, o corporativismo designa um sistema de representação de interesses cujas instituições se organizam num número limitado de categorias funcionalmente distintas e hierarquizadas, compulsórias e não concorrenciais, às quais o Estado concede o monopólio da representação em contrapartida de colaboração no exercício do controlo social e político (Schmitter, 1979, p. 7-52).

Esta definição clássica de corporativismo social permite uma distinção vincada em relação ao corporativismo político. Este último conceito é definido pelo mesmo autor como

[...] um sistema de representação política, baseado numa visão orgânica-estatista da sociedade, em que as suas unidades "orgânicas" (família, poderes locais, associações e organizações profissionais e instituições de interesses) substituem o modelo eleitoral, centrado no indivíduo e na representação e legitimidade parlamentares, tornando-se o principal ou complementar órgão legislativo ou consultivo do governo. (Schmitter, 1979, p. 87)

Menos estabelecido e dependente da formulação dos próprios doutrinadores é o conceito de corporativismo económico,cujo traço mais comum às anteriores categorias teóricas reside no organicismo e na oposição do homo corporativus, movido pelo interesse nacional e por valores supostamente comuns, ao homo economicus, protótipo do capitalismo liberal (Bastien; Cardoso, 2007, p. 120-127). Segundo esta argumentação elíptica, a reabilitação do corporativismo seria uma etapa necessária e imperativa do processo histórico que exigia uma nova ética da actividade econó- 
mica, fundada na regulação estatal da concorrência, na economia dirigida e na institucionalização autoritária dos interesses. Políticas comerciais proteccionistas e práticas de comércio de Estado destinadas a apoiar políticas sectoriais de autarcia haviam de completar este aparato. Os principais axiomas da economia política do corporativismo - uma superação frágil da síntese neoclássica, conjugada com diversos pressupostos da escola histórica alemã - residia nos princípios da "utilidade colectiva" e do “interesse nacional”, uma dogmática fácil de acomodar à demagogia dos fascismos (Garrido, 2018b, p. 34-51).

Em qualquer dessas formas de corporativismo,trata-se de definições ou categorias analíticas que podem não resistir à prova histórica e que consentiram uma evidente plasticidade. Na prática, a ideia corporativa inspirou a criação de aparelhos institucionais de administração económica fortemente controlados pelos Estados autoritários e confiados às suas oligarquias burocráticas.

\section{Corporativismo e economia dirigida internacional}

No plano económico, num contexto institucional precipitado pela crise da economia liberal dos anos vinte e trinta, o corporativismo participou da procura transversal de sistemas de coordenação do mercado interno e de limitação da concorrência. O controlo dos preços dos bens alimentares e de matérias-primas ligadas a programas de autarcia foi um elemento transversal aos corporativismos históricos vinculados a regimes autoritários e totalitários (Brito, 1989, p. 91-109).

$\mathrm{Na}$ Europa dos anos trinta, e não apenas no continente europeu, o liberalismo conhecia a sua primeira crise institucional sulcada pela "grande depressão". Essa instabilidade contagiou a própria "ciência económica", abalando os fundamentos da síntese neoclássica, que conheceram a partir de então uma clara contestação, ainda que pouco consequente a curto prazo.

Nessa época de grandes tensões e de súbita construção de regimes autoritários e totalitários em diversos países, as ideias corporativistas conheciam o seu segundo fôlego histórico. $\mathrm{O}$ corporativismo renascia das cinzas após um longo curso de apagamento, obviamente associado à natureza anticorporativa do Estado liberal, que em nome da liberdade 
do trabalho e das leis do mercado proibira as corporações, abrindo caminho ao sindicalismo de classe e a um vigoroso mutualismo laboral (Garrido, 2016a, p. 24-57; Viscardi, 2010, p. 23-39). Posteriormente, os Estados que se disseram corporativos proibiram os sindicatos livres e reprimiram as associações de socorros mútuos para resgatar as corporações (embora outra sorte de corporações), num exaltado regresso a um passado orgânico, feito de harmonias sociais, à imagem de um corpo. Ainda que evidenciem as contradições históricas do corporativismo, estes ciclos e contraciclos não deixam de provar a resiliência histórica das ideias corporativistas e a adaptabilidade das suas instituições.

Durante os anos vinte e particularmente nos primeiros anos da década de trinta, a ideia de uma "economia dirigida internacional", assente na Corporação como entidade semiautónoma capaz de substituir as bases institucionais do sistema capitalista liberal, foi muito difundida. Essa ambição de erguer um corporativismo económico transnacional - uma espécie de "internacional corporativista" - surgiu com especial vigor argumentativo nas obras de Giuseppe De Michelis (1935) e de Mihail Manoilesco (1934), entre outros destacados autores corporativistas. Nos diversos países que conheceram regimes de tipo fascista, a economia dirigida que se declarou corporativa instituiu modelos administrativos de regulação económica estatal ou uma economia dirigida por meio de instituições públicas e semipúblicas de direito corporativo. Esta contradição angular - obviamente deliberada, de forma a oferecer agilidade ao sistema - acompanhou o corporativismo económico em todos os casos em que ele marcou a natureza dos regimes corporativistas e fez parte das suas lógicas de poder sobre a sociedade (Gagliardi, 2010, p. 116-125).

No plano jurídico e das técnicas de governo da economia, o corporativismo trouxe um renovado fôlego a um novo tipo de intervencionismo económico do Estado, ou numa linguagem de Direito público, à "administração reguladora indirecta” (Moreira, 1997, p. 104-105). Os regimes corporativistas atribuíram às instituições corporativas poderes de regulação económica, mas fizeram-no no âmbito do Estado ou por meio das organizações corporativas, usando-as como poder de mediação. Essas instituições típicas de um modelo de "corporativismo de Estado" surgiram primeiramente com o fascismo, em Itália, a partir de 1923, e em Espanha, com a ditadura de Primo de Rivera, no mesmo ano. 
$\mathrm{Na}$ prática, os aparelhos burocráticos do corporativismo vieram pôr em ordem uma realidade económica já formada, cujos interesses se agitaram por diversas razões e em medida variável, em regra por dentro das associações de interesses criadas no âmbito da ordem liberal.

Uma breve comparação das soluções institucionais encontradas nos principais regimes corporativistas e uma resenha do confronto que a burocracia económica autoritária trouxe às relações entre o público e o privado talvez facilite a análise deste fenómeno transversal a diversas economias e sociedades do período entre as duas guerras.

\section{Como intervir na economia? Experiências nacionais comparadas}

Na convulsiva Itália de 1918 e 1919, surgiram de par os institutos nacionais de segurança social e solidariedade e os primeiros organismos de administração da economia. Volvidas as pretensões socialistas do "primeiro fascismo", que chegou a reclamar a nacionalização das empresas monopolistas e a participação dos trabalhadores nas decisões e benefícios das empresas, até 1926, pelo menos, o Partido Nacional Fascista abraçou o liberalismo económico com entusiasmo.

No começo do movimento fascista, em 1919, os capitalistas e industriais não foram dos mais animados com a ideia dos camisas-negras, nem sequer se mostraram muito generosos no financiamento aos militantes fascistas. Em outubro de 1922, já foram os dirigentes das organizações patronais (a Cofindustria, a Confederação Agrícola e a Associação Bancária) a exigir a entrega do governo a Mussolini, na expectativa de serem recompensados, em especial se o fascismo banisse os sindicatos de trabalhadores socialistas, como efectivamente aconteceu. Em 1925, a poderosa Cofindustria obteve do regime fascista o direito de representação de todos os patrões, passando a fazer parte dos organismos fascistas, mas sem se diluir no sistema corporativo. No ano seguinte, no contexto da legislação sindical elaborada por Alfredo Rocco, que completou a subordinação do trabalho e do capital ao Estado fascista, as confederações patronais adquiriram poderes inéditos de controlo político e administrativo sobre os dirigentes e funcionários das associações industriais de pequena escala ou de natureza provincial (Gagliardi, 2010, p. 39-40). 
No campo da economia, as batalhas pela "produção nacional" e por uma certa autarcia - conceito muito ambíguo e praticado segundo diversos entendimentos, mesmo dentro do mesmo regime - abriram caminho a um dirigismo económico crescente, sobretudo depois da substituição, em 1928, do ministro das Finanças Giuseppe Volpi, um homem de negócios de crença liberal, por Antonio Mosconi, um intervencionista feroz. Entretanto, a corporativização forçada das organizações de patrões e trabalhadores conduzida ao abrigo da Carta del Lavoro (1927) institui uma sindicalização assimétrica que perdurou até 1945. Nem nas empresas nem nas organizações profissionais havia qualquer representação conjunta de trabalhadores e patrões (Gagliardi, 2010, p. 39-43).

Tal como sucedeu noutros países, inclusive em democracias liberais, também em Itália a crise mundial apressou o dirigismo económico. $\mathrm{O}$ maior impulso institucional a essa economia dirigida de base corporativa residiu na criação do Conselho Nacional das Corporações, em março de 1930. O papel do Conselho implicou a coordenação das relações económicas entre as várias categorias de produtores, a regulação das relações entre patrões e assalariados e a acção assistencial dos sindicatos profissionais. Ainda que formalmente consultivo, na prática o Conselho assumiu diversos poderes normativos e de intervenção no comércio de Estado e nas relações económicas entre as instituições sindicais fascistas.

A organização da economia transalpina foi a partir de então ainda mais estatista e menos corporativa do que se fazia crer: assentou na criação de dezenas de cartéis e consórcios públicos de obediência oficiosa ao Partido Nacional Fascista.A lógica de organização desses cartéis de Estado foi sectorial, em regra por produtos, como sucedeu no caso português, que, em boa medida, seguiu a experiência italiana nestes aspectos institucionais (Garrido, 2018a, p. 124-141). Os Entes Nacionais do Arroz (1931), cuja campanha de fomento, dirigida pelo próprio Mussolini, inspirou uma tímida "campanha do arroz" em Portugal, os Entes da Celulose e do Papel (1935) e o da Beterraba Sacarina (1937) são exemplos da transversalidade dos sectores económicos abrangidos pela cartelização fascista.

Abrindo caminho a formas de corporativismo de Estado, o desespero da crise capitalista iniciada em 1929 fechou a economia italiana ao exterior. Precipitaram-se alianças de interesse entre o regime fascista e a grande indústria no sentido de a proteger da crise internacional e de 
estimular os industriais a colaborar em programas de fomento que podiam contar com um mercado interno protegido pelas pautas alfandegárias e, não tarde, estimulado pela guerra. Foi esse o papel do Instituto per la Ricostruzione Industriale (IRI), que, a partir de 1931, criou e geriu uma série de holdings de Estado em sectores tão decisivos como o aço, a construção naval e os transportes marítimos. Além disso, o IRI promoveu concentrações, fusões e consórcios de empresas (Zamagni, 2003, p. 298-300).

Na Alemanha, a Constituição da República de Weimar (1919-1933), a primeira constituição europeia a definir um ordenamento económico, ficara aquém das intenções de promover a auto-administração da economia. A administração autónoma de sectores industriais importantes e a representação paritária de patrões e trabalhadores nessas instituições foram presas fáceis para o estatismo totalitário nazi. Nos mais diversos domínios, incluindo as organizações interprofissionais de segurança social herdadas de Bismarck e nas câmaras económicas e profissionais, a tradição alemã de auto-administração foi destruída em 1933 (Moreira, 1997,p. 211-212). A nova política económica, conduzida pelo presidente do banco central alemão Hjalmar Schacht, ministro da Economia a partir de julho de 1934 e Plenipotenciário-Geral da Economia de Guerra a partir do ano seguinte, implicou um dirigismo económico estrito que não decorria apenas das circunstâncias gravosas da crise internacional, mas de ideias próprias.

Logo em 1933, todas as corporações públicas vindas do Império ou da República são abolidas. Nesse mesmo ano, o Estado nazi impõe a cartelização de numerosos sectores económicos através da lei dos cartéis obrigatórios e segundo uma lógica de economia dirigida totalitária.Tal como sucedeu na França de Vichy a partir de 1941, na Alemanha as corporações (nominalmente consideradas) foram a fórmula de organização da agricultura. A mais saliente foi a "corporação nacional da lavoura", um organismo de Estado que agrupou produtores, industriais e comerciantes registados no negócio de produtos essenciais ao abastecimento alimentar.

A solução corporativa foi partilhada quer pelos adeptos da autarquia económica, quer pela corrente de reformistas económicos do Partido Nazi, que, nas eleições de julho de 1932, haviam subscrito o Programa de Emergência Económica do NSDAP, no qual já se apontava para uma 
economia militarizada de defesa (Wehrwirtschaft), orientada para relançar a produção industrial e a procura interna - a guerra e o império continental (Noakes; Pridham, 1997, p. 262-264). Entre 1933 e 1939, além da destruição dos sindicatos operários e da implementação de uma "política económica de defesa" capaz de contribuir para a solução dos problemas do desemprego e da crise agrícola, os esforços do Partido Nazi centram-se na cooptação e mobilização das grandes empresas e elites de negócio para os programas de defesa e agressão.

Dominadas por líderes do Partido único, as Reich Guilds organizaram localmente cada ramo do comércio de produtos artesanais e alcançaram níveis intermédios de organização nas câmaras de comércio distritais, instituições de aparência corporativa. Assemelhavam-se aos grémios concelhios de distribuição e comércio criados em Portugal em 1939 (Garrido, 2010, p. 164-172). O enquadramento estatal das grandes empresas industriais, comerciais e de serviços, em especial da "indústria pesada", foi de natureza vertical, mas conheceu resistências por parte de alguns sectores de exportação.

A sedução de alguns sectores do Partido Nazi pelo corporativismo italiano não teve acolhimento na "Lei de preparação para a construção orgânica da economia alemã”, promulgada em novembro de 1934. Este diploma instituiu um amplo esquema de controlo político e institucional da economia do Reich, assente em cartéis de Estado dominados pelo Partido Nazi, cuja finalidade era alcançar uma hegemonia sobre todas as direitas e assegurar o controlo estatal da produção. As empresas foram organizadas regionalmente, em "distritos económicos", e no âmbito nacional, por grandes sectores ou cartéis colocados na dependência do Ministério da Economia: indústria, artesanato, comércio, bancos, seguros, energia e turismo.

Os sete cartéis coroaram o grande edificio da economia dirigida nazi. Num ambiente proteccionista fortemente institucionalizado pelo Estado totalitário, as empresas integradas executavam os programas públicos de aumento da produção e substituição de importações e participavam no programa de "nazificação" da sociedade. A tarefa nacional das empresas e patrões foi facilitada pela eliminação prévia dos velhos sindicatos operários que, zelosamente, as SA ajudaram a transformar em sindicatos nazis. Encimados por um Conselho Nacional do Trabalho e da Economia, os cartéis obrigatórios (Reich groups) tinham funções oficiais de 
organização da produção e de disciplina do mercado, mas não intervinham nas relações de trabalho e salários, tal como sucedia no sistema corporativo italiano e português.

Em Espanha, as primeiras experiências de corporativismo económico de Estado surgiram, como se disse, com a ditadura protofascista de Primo de Rivera (1923-1930). A partir de 1923 foram criados diversos consórcios de empresas, alguns dos quais obrigatórios, em sectores económicos e profissionais como o arroz e o pão (padarias), o carvão e os minérios de ferro e de chumbo. Esses cartéis de Estado tinham funções oficiais de regulação, disciplina, fiscalização e fomento proteccionista das respectivas actividades económicas. A maioria dessas organizações manteve-se durante a II República espanhola (1931-1936), mas contando com a participação associativa dos interessados. Algumas dessas instituições económicas foram cooptadas ou dimensionadas pelo regime franquista. Novamente debaixo de uma retórica corporativista (Taboas, 2011, p. 11-24).

Após a Guerra Civil, a ditadura franquista (1939-1976) impôs o regresso a várias formas de economia dirigida e fez uso da ideologia corporativa para reprimir a luta de classes e o "sindicalismo vermelho". A associação sindical e patronal foi proibida, ao passo que as câmaras de comércio e indústria e as organizações profissionais persistiram fora da organização corporativa.

Em geral, a organização económica e profissional espanhola foi oficialmente submetida a uma sindicalização vertical e assimétrica de patrões e operários. Embora semelhantes às congéneres italiana e portuguesa, as instituições corporativas espanholas acabariam por ser adaptadas, e não extintas, ao abrigo da Constituição democrática de 1978. A autarcia, entendida como prática instituída de nacionalismo económico que implicava uma industrialização assente nas prioridades de defesa nacional e a intervenção do Estado sobre os preços, câmbios e salários, foi o eixo da política económica do franquismo até finais dos anos cinquenta.

$\mathrm{Na}$ indústria, o nuevo Estado assumiu um papel dirigista ainda durante a fase da autarquía, mas serviu-se do Instituto Nacional de Industria (INI), criado em 1941, como instrumento fundamental da industrialização do país. A mobilização industrial para fins de defesa começara durante a Guerra Civil, seguindo uma lógica totalitária, mas modernizadora.Actuando como uma "holding de Estado", o INI criou grandes 
empresas nos sectores da energia, transportes e metalurgia, foi proprietário de numerosas indústrias e dirigiu investimentos públicos e privados até 1963, data em que o seu director político, o engenheiro naval Juan António Suanzes, rompeu com Franco e deixou o Instituto (Comín; Hernández, 2002 p. 23-46).

$\mathrm{Na}$ agricultura, as semelhanças do sistema corporativo franquista com o modelo português de economia agrária corporativista foram muito mais nítidas. Em Espanha foi crucial o papel político do Servicio Nacional del Trigo, criado em 1937, em plena Guerra Civil e debaixo de grandes proclamações contra o capitalismo liberal, que o nacionalismo franquista prometia submeter aos interesses nacionais. Tratava-se de um organismo de coordenação económica destinado a proteger a grande produção cerealífera e a intervir no mercado interno. O Servicio actuou como principal instrumento de intervenção do Estado no sector agrário e como instituição de defesa dos grandes proprietários andaluzes e estremenhos. Instituída em 1939, a política nacionalista de colonização de terras completou o quadro instrumental do corporativismo agrário espanhol. Tal como na Itália fascista e no Portugal salazarista, o controlo estatal das relações laborais por meio do sindicalismo vertical e tendo por base o Fuero del Trabajo (1938) foi prioritário e comum às diversas fases do franquismo.

Um pouco diferente é o caso do corporativismo francês do chamado regime de Vichy, que conheceu uma duração limitada e coincidente com a ocupação alemã. Em França, o corporativismo mostrou uma particular efervescência ideológica durante toda a década de trinta, em plena agonia da III República. Nesse período, exprimiram-se no espaço político gaulês importantes doutrinadores franceses da "ciência corporativa", que foi aplicada às organizações profissionais e a alguns sectores da actividade económica seguindo de perto a experiência portuguesa, como de resto admitiram diversos autores franceses (Kaplan; Minard, 2004, p. 5-31).

Embora tenha imitado algum discurso italiano e mantido o culto pelo sociologismo católico antimoderno de Albert de Mun e de René de La Tour du Pin, durante esses anos o corporativismo francês construiu a sua própria doutrina e aproximou-se do fascismo. Autores como Maurice Bouvier-Ajam e Gaétan Pirou (Pirou, 1934), ambos professores de Direito em Paris, juntamente com o economista católico François 
Perroux, traduzido em Portugal (Perroux, 1936), ocuparam-se não apenas da "questão operária" e da corporação em si mesma, mas também das organizações patronais e do conceito de "empresa corporativa".

Como demonstram os estudos de Pierre Rosanvallon, em França a tradição de governo institucional da economia e das profissões era muito anterior ao corporativismo de Vichy, remontando ao período napoleónico (Rosanvallon, 1990, p. 22-24). Alguns organismos oficiais de administração económica surgiram mesmo por iniciativa do governo da Frente Popular, em 1936, a exemplo do Office National Interprofessionnel $d u$ Blé. Este organismo, que o regime corporativista de Vichy manteve e adaptou, reunia representantes dos produtores de cereais, dos padeiros e moageiros, dos consumidores e da própria administração central. À semelhança da portuguesa Federação Nacional dos Produtores de Trigo, o Office du Blé detinha o monopólio da importação (e neste caso da exportação), fixava preços, intervinha no mercado de cereais actuando sobre a oferta e a procura, geria e licenciava os contingentes de vendas.

Entre 1940 e 1944, o governo corporativista do marechal Pétain procedeu ao enquadramento oficial da "economia nacional" e das profissões numa base corporativista que também se traduziu em organismos estatais. Os mais numerosos e actuantes foram os Comités de Organização Profissional. Criados em agosto de 1940 pelo ministro da Produção Industrial e do Trabalho, René Belin, eram organismos obrigatórios ou sindicatos públicos de empresas semelhantes aos grémios obrigatórios do sistema português, no qual Pétain se inspirou. O governo colaboracionista atribuiu aos Comités funções reguladoras da concorrência, bem como de intervenção e disciplina sobre os trabalhadores e patrões do sector. Cada organismo tinha um comissário do governo. Os Comités de Organização foram os principais instrumentos da economia dirigida deVichy; em alguns sectores, serviram o programa de "arianização" (Le Bot, 2007, p. 141-144).

Em 1940 nasceram também as primeiras corporações agrícolas de natureza sindical e de âmbito municipal. Eram agrupadas em uniões de base regional e, por fim, numa federação nacional. Tal como as ordens profissionais erigidas durante o regime deVichy, seguindo uma tradição anterior o "corporativismo nacional" criou câmaras de ofícios, de comércio e indústria. No sector agrícola, a herança interprofissional e estatista deVichy, hostil a qualquer lógica de autogoverno, abriu caminho 
a uma panóplia de organismos de coordenação económica que acabariam por persistir e multiplicar-se, constituindo hoje, em França, bons auxiliares da implementação da política agrícola comum da União Europeia (Moreira, 1997, p. 218-220).

\section{A grande crise e o problema da sobrevivência do capitalismo}

As ideias de "capitalismo organizado" (a grande empresa coordenada burocraticamente) e de "economia dirigida" (as instituições de administração directa ou indirecta do Estado) colheram no estatismo conjuntural da Grande Guerra um decisivo impulso. Mas é certo que encontraram no tumulto financeiro dos anos vinte e na grande crise de 1929 um terreno favorável de afirmação, quer nos domínios da teoria económica, quer no campo prático da política dos Estados.

A entrega de responsabilidades de disciplina e regulação económica a associações sectoriais de empresas e organizações de interesses principiou em vários países durante e após a I Guerra Mundial, mesmo à margem de qualquer ideologia corporativista, como sucedeu na Alemanha. Numa coabitação sancionada pelas próprias Constituições, a administração económica dos Estados passou a coabitar com uma administração corporativa da economia e das profissões. Este modelo institucional teve especial acolhimento nos países em que o Estado liberal mostrou uma dificuldade crescente em integrar os interesses na esfera política, entrincheirando-se na defesa dos aparelhos de Estado, dos parlamentos e das oligarquias partidárias. Foi a grande e lenta erosão do sistema liberal.

Entre as duas guerras mundiais, no clima de problemas e incertezas que Keynes resumiu em As consequências económicas da paz (Keynes, 1919), diversos académicos de renome, dirigentes políticos e a própria opinião pública questionaram a visão clássica do Estado liberal e ensaiaram alternativas ao modelo económico do liberalismo. O debate essencial residia na velha questão do futuro do capitalismo. Problema que, durante e após a I Guerra Mundial, não só regressou ao debate académico como habitou a discussão popular.

Tal como Schumpeter explicou em 1946, o problema da sobrevi- 
vência do capitalismo fora levantado, em primeiro lugar, por Marx e por outros socialistas e, de seguida, pela escola histórica alemã (Schumpeter, 1996, p. 188). Muito antes disso, e antes do colapso de 1929 surpreender os próprios economistas, já o próprio Schumpeter debatera a instabilidade do capitalismo, concluindo que o sistema capitalista, embora economicamente estável, esgotara as possibilidades de se aperfeiçoar enquanto sistema social, sendo previsível que se autodestruísse ou mesmo que se transformasse numa espécie de socialismo (Schumpeter, 1996, p. 42-66) ${ }^{1}$. Hipótese teórica que, no combate de ideologias que marcou as décadas de vinte e de trinta, serviria a alguns corporativistas para agitar o fantasma comunista.

A questão prática que assolava o sistema capitalista desde que ele se começara a transformar por efeito imanente - por contradição destrutiva das suas próprias dinâmicas - e por efeito exógeno da I Guerra Mundial e das suas sequelas económicas e sociais foi a da "sobrevivência institucional do capitalismo". Essa problemática ocupou muito os autores corporativistas, não tanto no campo da teoria pura, mas no plano instrumental (Spirito, 1933; Pirou, 1934). Não por acaso, a solução corporativa seria instituída de forma pragmática e aplicada prioritariamente nos sectores económicos onde se denunciaram problemas de concorrência destrutiva e rendas decrescentes.

A "crise do sistema" ou a "crise no sistema" - Keynes exprimiu e celebrizou a segunda interpretação - foi uma expressão muito presente na literatura económica do tempo. Seja do lado liberal reformista, seja entre os partidários da "terceira via" corporativa que tiveram a pretensão de erigir uma ciência económica nova.

Partindo do princípio comum de que seria necessário salvar o sistema capitalista de si próprio e da sua manifesta incapacidade para garantir o equilíbrio das forças económicas nacionais e internacionais num contexto de economia de mercado, os teóricos da "economia corporativa" defenderam um sistema capitalista organizado e coordenado pelo próprio Estado. Visto que o mercado deixara de cumprir a sua função reguladora do sistema económico e social e que a concorrência deixara de actuar como factor natural de equilíbrio entre a oferta e a procura,

1 As páginas indicadas correspondem ao artigo que Schumpeter publicou em 1928 no Economic Journal, que precisamente intitulou "A instabilidade do capitalismo". 
seria necessário criar uma instituição reguladora intermédia para realizar o "bem-estar colectivo", noção que na lógica do corporativismo autoritário dessa época implicava um "Estado forte" e garantir a "ordem social". A organização corporativa da economia seria um instrumento desse programa político de superação do sistema liberal.

O próprio Keynes, em The end of laissez-faire (Keynes, 1926) e noutros textos em que reflectiu acerca da natureza instável do capitalismo e sobre a crise que se instalara no sistema, exprimiu posições pragmáticas a favor de uma certa intervenção do Estado e de soluções institucionais de coordenação que alguns autores têm abusivamente identificado com o corporativismo. Fiel à ideia liberal de demarcação da economia do Estado, Keynes escreveu nesse opúsculo:

Creio que em muitos casos o tamanho ideal da unidade de controlo e organização da economia se situa algures entre o indivíduo e o Estado moderno. Entendo por isso que o progresso reside na criação e reconhecimento de organismos semipúblicos dentro do Estado. Proponho assim um regresso às concepções medievais das autonomias separadas. (Keynes, 1926, p. 41)

\section{A economia política dos corporativismos fascistas}

Do ponto de vista doutrinário, a adaptação de certos autores da "economia corporativa" italiana, em especial de Ugo Spirito, serviu para exprimir uma crítica à economia neoclássica conotada com o liberalismo e com a noção abstracta do homo economicus na intenção de legitimar o intervencionismo do Estado (Brito, 1989, p. 33-37).

Aos princípios neoclássicos de equilíbrio espontâneo do mercado e de livre concorrência opunha-se uma economia política pretensamente nova, assente no critério de caso governamental e na organização corporativa enquanto recurso da "economia dirigida". Economistas de relevo como Rodolfo Benini, Alberto De Stefani e Luigi Amoroso procuraram conjugar o abandono do modelo walrasiano de "concorrência perfeita" (do economista francês Léon Walras) e o individualismo metodológico dos neoclássicos, abrindo caminho a uma teoria da disciplina e da intervenção estatal sobre a actividade económica, a relação salarial e os preços. 
Laborando em argumentos dogmáticos, amiúde mais doutrinários do que teóricos, a maioria dos corporativistas, a exemplo dos italianos Spirito, Arias, Rocco, Bottai e De Michelis, bem como o romeno Manoilesco, que procurou elaborar uma teoria geral do corporativismo (Manoilesco, 1934, p. 11-18), recriminaram a falta de ligação do Estado liberal à vida social das nações e denunciaram o carácter inorgânico das instituições liberais.

Munidos desta crítica, os corporativistas afirmaram a impossibilidade de uma reorganização do sistema económico capaz de repor o equilíbrio do comércio internacional e a disciplina do "capital" e do "trabalho". Fizeram-no de acordo com uma concepção corporativista de equilíbrio económico e social, teoria de fundo moral que supunha a acção coordenadora de um Estado autoritário e que, na maioria dos autores, exprimia uma legitimação da fórmula italiana do "fascismo corporativista" (Manoilesco, 1934, p. 145-172).

Os teóricos mais comprometidos com a aliança política entre a "economia corporativa" e o fascismo chegaram a afirmar que todos os fenómenos económicos são estaduais. Ugo Spirito declarou o "Estado corporativo" e a "economia corporativa" (a tal "economia nova") realidades históricas indissociáveis, "frutos imprescindíveis do espírito moderno". Segundo o professor de Direito e Filosofia da Universidade de Roma, cuja obra principal foi traduzida em Portugal, a "economia corporativa" resolvia o problema social e político da antinomia entre o Estado e o indivíduo por ser um meio de "concretização orgânica cada vez maior da vida estadual da Nação” (Spirito, 1934, p. 59). Spirito criticava com insistência o princípio neoclássico do "individualismo utilitarista" e colocava em seu lugar a noção de "máximo bem-estar social", axioma que casou bem com o ideário orgânico-nacional do corporativismo autoritário.

Segundo este e outros economistas do corporativismo, ao imergir o Estado no indivíduo a "economia corporativa" daria um contributo inestimável para a eliminação da natureza transcendente do próprio Estado. Esse distanciamento e abstracção teriam condenado o Estado liberal a romper os seus elos com a vida económica e social, criando um vazio de representação que o corporativismo moderno deveria preencher.

De forma linear, esta argumentação doutrinária sobre a imanência do Estado na esfera privada (o indivíduo) e colectiva (a vida social) confluía 
numa exaltação da "economia corporativa" enquanto sistema económico inclusivo. Sugeria-se que a "economia nova", de par com a organização corporativa que a havia de instituir - que já a instituíra no fascismo italiano -, seriam pilares do Estado totalitário. Por sua vez, o fascismo-regime seria a expressão política natural de uma ciência económica nova, capaz de conjugar as autarcias nacionais com a estabilidade do sistema capitalista.

Segundo Gaétan Pirou, professor de Direito em Paris, na Europa de entre as guerras coabitavam duas correntes corporativistas: i) o corporativismo "puro" e "autónomo", cujo sistema se organizaria sem ingerência do Estado e por iniciativa dos grupos sociais interessados; ii) o corporativismo como aparelho económico subordinado ao poder político, ou seja, estreitamente controlado pelo Estado (Pirou, 1937, p. 8-13).

Entre os anos vinte e trinta, especialmente em França, as ideias corporativistas também se alimentaram da nebulosa neossocialista que compreendia pensadores como o francês Marcel Déat e o belga Henri de Man, bem como o movimento de extrema-direita francesa da "Ordem Nova", que denunciou com insistência a ruptura moral entre capital e trabalho que se instalara nas democracias industriais e nas próprias economias e sociedades periféricas (Dard, 2011 p. 67-87).

As experiências em curso nos diversos países europeus que se declaravam corporativistas iam colocando em evidência a supremacia desta segunda via, um realismo social e económico fortemente instituído e dirigista. Na prática, esses sistemas de corporativismo de Estado implicaram um compromisso da ideologia corporativa com a praxis política dos regimes autoritários e totalitários. Numa perspectiva mais revolucionária ou mais reaccionária, o corporativismo instituído revelou-se secular e burocrático,acabando por limitar os ideais corporativos de raiz cristã, de acento social e solidarista.

\section{O caso português: a organização corporativa do Estado Novo}

Embora matizada pelo pragmatismo do chefe do governo Oliveira Salazar e pela cautela com que o ditador português se procurou demarcar da natureza totalitária e pagã do fascismo de Mussolini, a perspectiva 
imanente da "economia corporativa" e a dialéctica entre Estado e indivíduo foram os princípios que a doutrina corporativa portuguesa mais adoptou para proclamar uma "economia nova".

Nas suas pretensões regeneradoras do sistema capitalista-liberal, a teoria económica corporativa chegou a pugnar por um homo corporativus, uma nova condição da natureza humana capaz de garantir uma ordem económica e social fundada na comunhão entre o indivíduo e o Estado. Este último argumento doutrinal não só permitiu reafirmar a supremacia do conceito de "economia nacional" - colhido na velha escola histórica alemã de Economia Política, em especial na obra de Friedrich List (Hodgson, 2001, p. 56-64) -, como serviu para declarar a ordem corporativa a única fórmula político-institucional do "bem-estar colectivo".

Os corporativistas mais moderados colocaram, porém, o assento na organização corporativa como entidade semiautónoma dos poderes públicos. Consideraram que esse aparelho institucional deveria ser dotado de prerrogativas próprias de regulação económica a exercer através das Corporações. Foi nesse sentido que Manoilesco se referiu ao corporativismo como um “capitalismo de organização” (Manoilesco, 1934, p. 11-13). Essa expressão era muito comum na literatura económica da época, nomeadamente na obra de Schumpeter, que em 1928 a usou para distinguir a natureza institucional do capitalismo do século XX do capitalismo concorrencial oitocentista que, em rigor, fora o suporte do Estado liberal.

Apesar das diferenças dos aparelhos institucionais que a economia dirigida de base corporativa conheceu nos diversos países em que existiu, a regulação corporativa da economia teve como elemento comum, precisamente, a disciplina da concorrência. $\mathrm{O}$ controlo dos preços, a direcção política e administrativa da actividade económica e da iniciativa empresarial, o condicionamento proteccionista das importações e exportações e as práticas de comércio de Estado foram expressões contundentes dessa aversão à concorrência. $\mathrm{Na}$ experiência corporativa portuguesa, quer enquanto sistema económico-social quer enquanto organização assente em cartéis económicos instituídos, encontram-se muitos exemplos dessas práticas de inibição da concorrência (Garrido, 2018b, p. 99-132).

Mais do que uma ideologia de legitimação destinada a preencher o vazio da indecisa ditadura militar de 1926-1933, o corporativismo por- 
tuguês cedo mostrou o que era e ao que vinha: um dispositivo de consolidação do regime autoritário, um expediente de liquidação do sindicalismo de classe, associativo e anarquista, um recurso de dominação e arbitragem de interesses, um instrumento de arrumação da "economia nacional".

Neste intervencionismo dirigista sobressaíram os organismos de coordenação económica, elementos de administração indirecta do Estado que, embora anunciados como provisórios e nessa medida "pré-corporativos", acabaram por ter uma vida mais longa do que os próprios organismos corporativos. Esse foi um dos desvios mais controversos do sistema corporativo português, sempre discutido e jamais reparado, nem mesmo durante o marcelismo (1968-1974). Corporativista convicto, Marcello Caetano acabaria por criar diversos organismos de coordenação económica, conjugando a abertura aos mercados externos europeus com o reforço do intervencionismo vertical em diversos sectores da economia.

A organização corporativa portuguesa acabou por ser apenas um modo residual de regulação, um instrumento auxiliar da coordenação económica estatal. Dito de outro modo, conclui-se que o Estado Novo criou uma economia nacional que declarou corporativa, mas na verdade instituiu uma vasta rede de instituições que evidenciaram lógicas e práticas de direcção económica de natureza estatal.

Segundo a sua utopia doutrinária, o corporativismo português deveria edificar um sistema de autoadministração da economia composto por organismos profissionais dotados de poderes públicos. A realidade ficou muito longe desse modelo ideal.

O roteiro documental vertido no Quadro 1 identifica um total de 2449 instituições corporativas criadas pelo Estado Novo. Se muitas foram transformadas, fundidas ou extintas até 1974, quando ocorreu a Revolução de Abril ainda existiam cerca de 2300 organismos, o que diz bem da perenidade da organização corporativa e da sua penetração social. A expressão numérica das pequenas Casas do Povo neste imenso conjunto (cerca de $50 \%$ do total) não dispensa atenção ao peso dos demais organismos - em especial dos que dependiam directamente do Ministério da Economia - no edificio corporativo que o Estado autoritário ergueu. Fora desta pirâmide distorcida, acomodaram-se os organismos de coordenação económica, as mais decisivas instituições da economia dirigida do regime de Salazar e Caetano. 


\begin{tabular}{|c|c|}
\hline \multicolumn{2}{|c|}{ Quadro 1 - Instituições do corporativismo português (1933-1974) } \\
\hline ORGANIZAÇÃO PRÉ-CORPORATIVA-ESTATAL & NÚMERO DE INSTITUIÇÕES \\
\hline Organismos de Coordenação Económica & 24 \\
\hline \multicolumn{2}{|l|}{ ORGANIZAÇÃO CORPORATIVA } \\
\hline \multicolumn{2}{|l|}{ Organismos primários (capital): } \\
\hline Grémios obrigatórios & 143 \\
\hline Grémios facultativos do comércio e indústria & 307 \\
\hline Grémios da lavoura & 236 \\
\hline \multicolumn{2}{|l|}{ Organismos primários (trabalho): } \\
\hline Sindicatos nacionais & 423 \\
\hline Casas do Povo & 1161 \\
\hline Casas dos Pescadores & 31 \\
\hline \multicolumn{2}{|l|}{ Organismos intermédios: } \\
\hline Federações e Uniões de Grémios & 92 \\
\hline Federações e Uniões de Sindicatos & 32 \\
\hline \multicolumn{2}{|l|}{ Organismos superiores: } \\
\hline Corporações & 11 \\
\hline Número total de instituições & 2449 \\
\hline Número total de instituições & 2449 \\
\hline
\end{tabular}

Fonte: Boletim do Instituto Nacional do Trabalho e Previdência (1933-1974).

Este mapa geral impressiona pelo número e diversidade dos organismos. Mas há que notar o flagrante contraste entre as realidades institucionais da organização corporativa e a pirâmide desenhada pelos doutrinadores que, idealmente, seria coroada pelas Corporações e teria na base os organismos corporativos primários do "capital"e do "trabalho". As instituições corporativistas (incluindo nesta designação aberta os próprios organismos de coordenação económica) assumiram basicamente funções económicas (de intervenção, direcção e regulação) e funções profissionais (representação sindical ou outra e previdência social).

A funcionalidade política dos organismos foi transversal a toda a organização corporativa. A natureza autoritária e oligárquica dos organismos corporativos e de coordenação económica expressou-se de maneira fáctica, através dos seus dirigentes e das relações de dependência que os agentes económicos e sociais mantinham com o sistema político 
do regime. Essa lógica política revelou-se também nos dispositivos antidemocráticos que condicionavam a representatividade das instituições corporativas: homologação governamental dos dirigentes, aprovação superior dos estatutos e existência de delegados do governo nos grémios obrigatórios e federações.

A organização corporativa da economia, cuja base assentou numa organização dualista composta por sindicatos de trabalhadores e patrões, dispensava às Corporações uma função de representação conjunta e harmoniosa de ambos os polos sociais. Manuel de Lucena salientou que “o acento tónico da organização corporativa portuguesa está na economia, que bate e de longe todos os outros sectores organizados" (Lucena, 1976, p. 162). Se o corporativismo português começou por ser social, na verdade a sua institucionalização incidiu sobretudo na vida económica.

Centenas de instituições da organização corporativa, seguramente as mais decisivas para a longevidade do regime, ficaram na dependência do Ministério do Comércio e Indústria, depois da Economia, ou seja, actuaram rente ao governo. Porém, a parte mais numerosa da organização, aquela que foi constituída por organismos de representação profissional e previdência, em especial pelos sindicatos e Casas do Povo, dependia do Instituto Nacional do Trabalho e Previdência (de 1933 a 1950) e do Ministério das Corporações (de 1950 em diante). Por vontade de Salazar, o Instituto Nacional do Trabalho e Previdência funcionou sempre na dependência directa da Presidência do Conselho de Ministros assegurando a fiscalização do aparelho corporativo numa lógica de conciliação administrativa e repressiva do "capital" e do "trabalho".

Portugal conheceu uma organização económica estatal de sugestões corporativas que ficou muito aquém do anunciado "Estado Corporativo". Construção inacabada e imperfeita, este último serviu para reprimir conflitos sociais de natureza classista e para prevenir o confronto aberto dos interesses. Em rigor, o "Estado de ordem" português, semiliberal na economia e antiliberal na política, achou nas ideias e instituições corporativas um expediente para se erguer e durar.

Eclética e pragmática, a "economia corporativa portuguesa" mostrou-se uma composição frágil de referências colhidas em correntes diversas do pensamento económico. Tratou-se de uma síntese com escassa autonomia teórica em relação ao modelo neoclássico que servira a ordem económica liberal, cujas noções de "concorrência perfeita", "equilíbrio 
espontâneo dos mercados" e "bem-estar individual" os corporativistas criticaram com veemência de forma a justificar o intervencionismo dirigista do Estado.

Em Portugal e noutros países, a ideologia económica corporativa permaneceu presa a um discurso doutrinário construído em torno do dogma do "interesse nacional", a tradução política da noção de "utilidade social colectiva", axioma central no pensamento económico dos corporativistas (Brito, 1989, p. 37-39). O nacionalismo autoritário de base corporativa deveria opor-se ao internacionalismo operário e socialista. A justa harmonia dos interesses só podia ser obtida no plano nacional - isto é, dentro da ordem e do equilíbrio nacional - e nunca por meio de organizações internacionais de operários ou trabalhadores.

Podemos assim concluir que o Estado Novo português criou e impôs uma ordem económica corporativa assente numa lógica funcional e instrumental. Numa expressão elucidativa do sentido pragmático com que a ideia corporativa serviu o projecto de reconstrução do Estado (a edificação do "Estado Novo"), Salazar sugeriu em 1933 que uma das tarefas da "República corporativa" seria a de amarrar os interesses ao Estado para reconstituir a autoridade pública.

\section{Referências}

BASTIEN, Carlos; CARDOSO, José Luís. From homo economicus to homo corporativus: a neglected critique of neoclassical economics. The Journal of Socio-Economics, n. 36, p. 120-127, 2007.

BEREND, Ivan. An economic history of twentieth-century Europe: economic regimes from laissez-faire to globalization. Cambridge: Cambridge University Press, 2006.

BRITO, José Maria Brandão de. A industrialização portuguesa do pós-guerra (1948-1965): o condicionamento industrial. Lisboa: Publicações Dom Quixote, 1989.

COMÍN, Francisco; HERNÁNDEZ, Mauro; LLOPIS, Enrique (eds.). Historia Económica de España, siglos X-XX. Barcelona: Crítica, 2002.

DARD, Olivier. Le corporatisme dans l'aire francophone, dir. Olivier Dard, Bern: Peter Lang, 2011.

GAGLIARDI, Alessio. Il corporativismo fascista. Roma-Bari: Laterza, 2010.

GARRIDO, Álvaro. Cooperação e solidariedade: uma história da economia social. Lisboa: Tinta da China, 2016a.

GARRIDO, Álvaro.O corporativismo na história e nas ciências sociais:uma reflexão 
crítica partindo do caso português. Estudos Ibero-Americanos, v. 42, n. 2, p. 387-408, maio-ago. 2016b.

GARRIDO, Álvaro. O Estado Novo e a Campanha do Bacalhau. Lisboa: Círculo de Leitores/Temas \& Debates, 2010.

GARRIDO, Álvaro. A institucionalização do social no Estado Novo português: previdência corporativa e seguros sociais voluntários. Estudos Históricos, v. 31, n. 64, p. 197-218, maio-ago. de 2018a.

GARRIDO, Álvaro. Queremos uma economia nova! Estado Novo e corporativismo. Porto Alegre: Edipucrs, 2018b.

HODGSON, Geoffrey. How economics forgot history: the problem of historical specificity in social science. London: Routledge, 2001.

KAPLAN, Steven; MINARD, Philippe (Org.). La France, malade du corporatisme? XVIII ${ }^{\text {- }}$ -XX ${ }^{\mathrm{e}}$ siècles. Paris: Éditions Belin, 2004.

KEYNES, John Maynard. The economic consequences of peace. Londres: Macmillan, 1919.

KEYNES, John Maynard. The end of laissez-faire. Londres: Hogarth Press, 1926.

LE BOT, Florent. La fabrique réacctionnaire: antisémitisme, spoliations et corporatisme dans le cuir (1930-1950). Paris: Sciences Po Les Presses, 2007.

LUCENA, Manuel de. A evolução do sistema corporativo português. Lisboa: Perspectivas \& Realidades, 1976.

MANOILESCO, Mihail. Le sécle du corporatisme: doctrine du corporatisme intégral et pur. Paris: Félix Alcan, 1934.

MICHELIS, Giuseppe de. La corporation dans le monde: économie dirigée internationale. Paris: Les Éditions Denoel et Steele, 1935.

MOREIRA,Vital. Auto-regulação profissional e administração pública. Porto: Livraria Almedina, 1997.

NOAKES, Jeremy; PRIDHAM, Geoffrey (Org.). Nazism, 1919-1945, v. 2. Exeter: University of Exeter Press, 1997.

PASETTI, Matteo. L'Europa corporative: una storia transnazionale tra le due guerre mondiali. Bolonha: Bononia Unibersity Press, 2016.

PERROUX, François. Lições de economia política. Coimbra: Coimbra Editora, 1936.

PINTO, António Costa (Org.). Corporatism and fascism: the corporatist wave in Europe. Londres: Routledge, 2017.

PIROU, Gaétan. Corporatisme. Revue d'Économie Politique, p. 1329-1366, 1937.

PIROU, Gaétan. La crise du capitalisme. Paris: Receuil, 1934.

ROSANVALLON, Pierre. L'État en France de 1789 à nos jours. Paris: Éditions du Seuil, 1990.

SCHMITTER, Philippe. Still the century of corporatism? In: SCHMITTER, Philippe; LEHMBRUCH, Gerhard (Org.). Trends towards corporatist intermediation: contemporary political sociology, v. 1. London: Sage Publications, p. 7-52, 1979.

SCHUMPETER, Joseph. Ensaios: empresários, inovação, ciclos de negócio e evolução do capitalismo. Oeiras: Celta Editora, 1996. 
SPIRITO, Ugo. Princípios fundamentais de economia corporativa. Lisboa: Livraria Clássica Editora, 1934.

TABOAS, Daniel Lanero.Historia dun ermo associativo: labregos, sindicatos verticais e políticas agrarias en Galicia baixo o franquismo. Madrid: Eurodiciones, 2011.

VISCARDI, Cláudia. O estudo do mutualismo: algumas considerações historiográficas e metodológicas. Mundos do trabalho, v. 2, n. 4, p. 23-39, ago.-dez. 2010.

ZAMAGNI,Vera. The economic history of Italy, 1860-1990. Londres: Oxford University Press, 2003. 